\title{
Editorial
}

\section{Preventing Surgical-Site Infections: The Importance of Timing and Glucose Control}

\author{
E. Patchen Dellinger, MD
}

\begin{abstract}
Our understanding of the physiology of wound healing and wound infection and the most effective strategies to reduce the risk of wound infection have progressed over a very long time. Perhaps the earliest significant advance in this field was the recognition of the role of bacteria in wound infection and the subsequent development first of antisepsis and then of asepsis. Important milestones in this progression included the development of the steam sterilizer, the introduction of rubber gloves for the surgical team, and effective techniques for skin preparation at the operative site. These developments occurred so long ago that no one currently practicing either surgery or infection control was present for their introduction. Nevertheless, occasional failures in their application, with resulting clusters of surgical-site infections (SSIs), serve to remind us of their continued importance.

The introduction of antibiotics in the 1950s did not bring the promise of reduced SSIs, as many had hoped, until laboratory studies by John Burke in the $1960 \mathrm{~s}^{1}$ and subsequent prospective clinical trials ${ }^{2,3}$ demonstrated the elements required to achieve reduced infection rates through the use of prophylactic antibiotics. Hundreds of clinical trials since that time have refined our understanding of the most effective and appropriate methods of employing these useful drugs to prevent SSIs. ${ }^{4,5}$ Although appropriate use of prophylactic antibiotics can reduce infection rates by $40 \%$ to $80 \%,{ }^{3-7}$ there is abundant evidence that unacceptable infection rates can result despite antibiotic administration in settings where wound management and antisepsis break down. 3,8

In the 1970 s and before, extensive hair removal with a razor at and around the operative site was common, in the belief that it improved local antisepsis, and the shaving often occurred the night before the operation. Several pub-
\end{abstract}

lications in the 1980 s clearly demonstrated that this practice increased the risk of infection by promoting the growth of bacteria in microscopic (or macroscopic) cuts induced by the razor and populated by bacteria from hair follicles. ${ }^{9.11}$ Current practice encourages no hair removal or limited hair removal occurring immediately prior to the operative procedure using clippers or depilatories rather than a razor. The effect of hair removal is most obvious in clean operative procedures, where exposure to endogenous bacterial is limited to skin flora. Despite this, one still can find razors stocked routinely in operating room supply carts in many modern hospitals and medical centers.

A number of investigators have demonstrated a strong association between the colonization of the nares with Staphylococcus aureus and subsequent staphylococcal SSIs following clean operative procedures. ${ }^{12,13}$ Despite the promise suggested by the strategy of eliminating or suppressing carriage prior to scheduled clean operative procedures and several papers with historical controls that show a reduction in SSIs, we do not have any definitive, prospective publication demonstrating efficacy in a clinical setting to date. Finding and targeting the high-risk population in an efficient and cost- effective manner may be part of the problems. In addition, it may be that strategies aimed primarily at the nares fail to deal with simultaneous colonization of the axillae, groin, or rectum.

Temperature control in the operating room did not receive much attention in the past, but a recent study has demonstrated the value of preventing hypothermia during major operative procedures. When patients undergoing colectomy were randomized to have their temperature actively managed to maintain it as close as possible to $37^{\circ} \mathrm{C}$, the SSI rate was approximately one third that of patients whose temperature was allowed to fall during the opera-

From the University of Washington Medical Center, Seattle, Washington.

Address reprint requests to $E$. Patchen Dellinger, $M D$, Professor and Vice Chairman, Department of Surgery, University of Washington Medical Center, Box 356410, Room BB 428, 1959 NE Pacific St, Seattle, WA 98195-6410.

O1-ED-144. Dellinger EP. Preventing surgical-site infections: the importance of timing and glucose control. Infect Control Hosp Epidemiol 2001;22:604-606. 
tion. ${ }^{14}$ Active warming of patients is now common in operating rooms throughout the United States. The exact reason for the reduction in wound infection rates with active warming of patients is not known, but it is known that subcutaneous blood flow and oxygen tension levels are higher in normothermic patients compared with hypothermic patients.

The relation between tissue oxygen levels and the risk of wound infection has been extensively investigated by Thomas Hunt and a number of colleagues since the late 1970s. ${ }^{15,16}$ Among the interesting observations of these workers was the fact that, in animal models, higher tissue oxygen levels resulted in lower infection rates than normal oxygen levels and that reduced oxygen levels resulted in higher infection rates and more severe infections. They also observed that this effect, like that of prophylactic antibiotics, was maximum during the time of operation and for a short time afterward, and did not affect the incidence of SSI if instituted after an interval following the operative procedure. This is consistent with the concept of the decisive period of wound healing and infection risk proposed by Miles and Burke many years ago. ${ }^{17,18}$ A subsequent study, again in patients having colectomy, demonstrated that the provision of high levels of inspired oxygen $(80 \%)$ in the operating room and for 2 hours following the operation resulted in an SSI rate less than one half that of patients treated in the same manner but with $30 \%$ inspired oxygen. ${ }^{19}$ Again, the effective period of treatment was demonstrated to be the immediate perioperative period.

The association of diabetes mellitus with an increased risk for SSI has been recognized for many years. More recently, as reviewed in the article by Latham et al in this issue, granulocyte functions, including adherence, chemotaxis, phagocytosis, and bactericidal activity, have been shown to be affected by hyperglycemia. ${ }^{20}$ Others have shown that improved glucose control achieved with an insulin infusion in the perioperative period can reduce SSI rates in diabetic cardiac surgery patients when compared with historic controls. ${ }^{21}$ Latham and colleagues prospectively gathered hemoglobin A1c values on 1,000 diabetic and nondiabetic cardiac patients prior to planned coronary artery bypass or valve procedures. They confirmed the previously observed increase (almost threefold) in infection rates in diabetics. They also found that $4.2 \%$ of the patients had previously undiagnosed diabetes, and the infection rate in these patients was equal to the rate in diagnosed diabetics. More interestingly, they demonstrated that the greatest risk for SSI correlated with postoperative hyperglycemia (blood glucose levels greater than $200 \mathrm{mg} / \mathrm{dL}$ ) rather than with the level of hemoglobin Alc or with preoperative hyperglycemia (they apparently did not have intraoperative glucose levels available). This appears to correlate with data regarding the time course of antibiotic efficacy and the effect of temperature and oxygen levels. The most important blood glucose measurements were the postoperative measurements rather than a measure of long-term control (hemoglobin A1c) or even of hyperglycemia in the preoperative period. These authors found a strong association in both diabetic and nondiabetic patients between hyperglycemia at least once during the 48 hours following operation and SSI. It would be very interesting to explore whether the critical period for glucose control extends to 48 hours or whether, like antibiotics, temperature, and oxygen, the effect is much stronger during and shortly after the operative procedure. One can imagine a future study in which frequent measurements of blood glucose are made in all patients (diabetic and nondiabetic) during the operative procedure and in the postanesthesia-care unit (recovery room) either as an observational study such as this one or with intensive intervention. This could shed further light on the decisive period during which tight glucose control has the greatest influence on the risk of SSI. An ideal intervention trial would compare two different algorithms with different goals for glucose management, comparing infection rates and complications or difficulties associated with tighter glucose control.

Latham and colleagues point out that many of the known risk factors for SSI are factors that cannot be changed by the physician such as gender, age, obesity, underlying diseases, and duration of surgery. ${ }^{20}$ However, over the past century and particularly the last 40 years, we have learned how to limit the access of endogenous bacteria to the wound, discourage their proliferation when they do get there, and optimize host physiology through attention to nutrition in some highly selected cases and to temperature and oxygenation in all cases. Latham found that $159(48 \%)$ of 328 diabetic patients and $139(12 \%)$ of 654 nondiabetic patients experienced hyperglycemia in the first 48 postoperative hours. In other words, $47 \%$ of patients who experienced postoperative hyperglycemia were not diabetic, and $30 \%$ of all patients undergoing cardiac surgery experienced at least one postoperative hyperglycemic episode. Each group of hyperglycemic patients (diabetic and nondiabetic) experienced an approximately twofold higher SSI rate than the comparable group that did not experience hyperglycemia. Thirty percent of the excess infections attributable to hyperglycemia occurred in nondiabetic patients. If the 298 patients with postoperative hyperglycemia had been kept below $200 \mathrm{mg} / \mathrm{dL}$ by intensive perioperative glucose monitoring and control, and if that control had reduced their infection rate to the rate observed in this study for patients without postoperative hyperglycemia, there would have been a reduction of 19 infections out of 72 , or $26 \%$. That is a difference worth confirming and achieving.

Since this editorial was written, two highly relevant and supportive articles to the points made above have been published. ${ }^{22,23}$

\section{REFERENCES}

1. Burke J. The effective period of preventive antibiotic action in experimental incisions and dermal lesions. Surgery 1961;50:161-168.

2. Bernard H, Cole W. The prophylaxis of surgical infection: the effect of prophylactic antimicrobial drugs on the incidence of infection following potentially contaminated operations. Surgery 1964;56:151-157.

3. Polk HC Jr, Lopez-Mayor JF. Postoperative wound infection: a prospective study of determinant factors and prevention. Surgery 1969;66:97-103. 
4. ASHP therapeutic guidelines on antimicrobial prophylaxis for surgery. ASHP Commission on Therapeutics. Clin Pharm 1992;11:485-513.

5. Dellinger EP. Gross PA, Barrett TL, Krause PJ, Martone WJ, McGowan $\mathrm{JE} \mathrm{Jr}$, et al. Quality standard for antimicrobial prophylaxis in surgical procedures. The Infectious Diseases Society of America. Infect Control Hosp Epidemiol 1994;15:182-188.

6. Platt R, Zucker JR, Zaleznik DF, Hopkins CC, Dellinger EP, Karchmer AW, et al. Prophylaxis against wound infection following herniorrhaphy or breast surgery. I Infect Dis 1992;166:556-560.

7. Clarke JS, Condon RE, Bartlett JG, Gorbach SL, Nichols RL, Ochi S. Preoperative oral antibiotics reduce septic complications of colon operations: results of prospective, randomized, double-blind clinical study. Ann Surg 1977;186:251-259.

8. Hojer $\mathrm{H}$, Wetterfors J. Systemic prophylaxis with doxycycline in surgery of the colon and rectum. Ann Surg 1978:187:362-368.

9. Alexander JW, Fischer JE, Boyajian M, Palmquist J, Morris MJ. The influence of hair-removal methods on wound infections. Arch Surg 1983:118:347-352

10. Balthazar ER, Colt JD, Nichols RL. Preoperative hair removal: a random prospective study of shaving versus clipping. South MedJ 1982;75:799-801.

11. Olson MM, MacCallum J, McQuarrie DG. Preoperative hair removal with clippers does not increase infection rate in clean surgical wounds. Surg Gynecol Obstet 1986;162:181-182.

12. Kluytmans JA, Mouton JW, Ijzerman EP, Vandenbroucke-Grauls CM, Maat AW, Wagenvoort JH, et al. Nasal carriage of Staphylococcus aureus as a major risk factor for wound infections after cardiac surgery. J Infect Dis 1995;171:216-219.

13. Wenzel RP, Perl TM. The significance of nasal carriage of Staphylococcus aureus and the incidence of postoperative wound infection.J Hosp Infect 1995;31:13-24.

14. Kurz A, Sessler DI, Lenhardt R. Perioperative normothermia to reduce the incidence of surgical-wound infection and shorten hospitalization. Study of Wound Infection and Temperature Group [see comments]. $N$ Engl J Med 1996;334:P1209-P1215.

15. Knighton DR, Halliday B, Hunt TK. Oxygen as an antibiotic: the effect of inspired oxygen on infection. Arch Surg 1984;119:199-204.

16. Knighton DR, Halliday B, Hunt TK. Oxygen as an antibiotic: a comparison of the effects of inspired oxygen concentration and antibiotic administration on in vivo bacterial clearance. Arch Surg 1986;121:191-195.

17. Burke J, Miles A. The sequence of vascular events in early infective inflammation. J Path and Bact 1958;76:1.

18. Miles A, Miles E, Burke J. The value and duration of defence reactions of the skin to the primary lodgement of bacteria. Br J Exp Pathol 1957;38:79-96.

19. Greif R, Akca O, Horn EP, Kurz A, Sessler DI. Supplemental perioperative oxygen to reduce the incidence of surgical-wound infection. Outcomes Research Group [see comments]. N Engl J Med 2000;342: 161-167.

20. Latham R, Lancaster AD, Covington JF, Pirolo JS, Thomas CS Jr. The association of diabetes and glucose control with surgical-site infections among cardiothoracic surgery patients. Infect Control Hosp Epidemiol 2001;22:607-612.

21. Furnary AP, Zerr KJ, Grunkemeier GL, Starr A. Continuous intravenous insulin infusion reduces the incidence of deep sternal wound infection in diabetic patients after cardiac surgical procedures [see comments]. Ann Thorac Surg 1999;67:352-360; discussion 360-362.

22. Melling AC, Ali B, Scott EM, Leaper DJ. Effects of preoperative warming on the incidence of wound infection after clean surgery: a randomised controlled trial. Lancet 2001;358:876-880.

23. Van den Berghe G, Wouters P, Weekers F, Verwaest C, Bruyninckx F, Schetz $\mathrm{M}$, et al. Intensive insulin therapy in critically ill patients. $N$ Engl $J$ Med 2001;345:1359-1367. 